\title{
Clinical analysis of severe COVID-19 patients
}

\author{
Hao Wang ${ }^{\mathrm{a}}$, Bin Sun ${ }^{\mathrm{a}, *}$, Xiayuan $\mathrm{Li}^{\mathrm{a}}$, Yun Wang ${ }^{\mathrm{b}}$ and Zhengping Yang ${ }^{\mathrm{a}}$ \\ antensive Care Unit, Qinghai Provincial People's Hospital, Xining, Qinghai, China \\ ${ }^{\mathrm{b}}$ Digestive System Department, Qinghai University Affiliated Hospital, Xining, Qinghai, China
}

\begin{abstract}
.
BACKGROUND: Patients with unexplained pneumonia appeared in Wuhan, Hubei Province at the end of 2019.

OBJECTIVE: To analyze the clinical data of patients with severe COVID-19.

METHODS: Medical records of 28 severe patients admitted to the intensive care unit of Wuhan Xinzhou District People's Hospital were collected from January 31 to March 17.

RESULTS: The mortality rate of severe patients in our study was 39.3\%. There were statistically significant differences in age, admission systolic blood pressure, lymphocyte count, albumin, total bilirubin, and lactate dehydrogenase between the death group and the survival group $(P<0.05)$. There were statistically significant differences in APACHE II, CURB-65, SOFA, respiratory frequency, systolic pressure, platelet, procalcitonin, albumin, creatinine, creatine kinase isoenzyme, lactate dehydrogenase, chloride ion, prothrombin time, international normalized ratio, arterial partial pressure of oxygen, and FiO2 at ICU between the death group and the survival group $(P<0.05)$.

CONCLUSIONS: Fever and cough are the main symptoms, which is useful for predicting the prognosis to dynamically measure the APACHE II, CURB-65, SOFA, respiratory frequency, lymphocyte count, platelet, lactate dehydrogenase, and coagulation tests. The drugs that protect the liver and heart may improve the survival rate of patients with severe COVID-19.
\end{abstract}

Keywords: Coronavirus disease 2019, critical illness, prognosis

\section{Introduction}

Patients with unexplained pneumonia appeared in Wuhan, Hubei Province at the end of 2019. The pneumonia spread rapidly in Wuhan, and most patients had a history of contact with the South China Seafood Market. Since then, more and more patients developed symptoms like fever and cough. In January 2020, the Chinese Center for Disease Control and Prevention (CDC) announced that the pathogen was a new type of coronavirus, which was subsequently named 2019-nCoV by the WHO [1]. As the situation worsened, the World Health Organization declared the outbreak a "Public Health Emergency of International Concern" (PHEIC). In February 2020, International Committee on Taxonomy of Viruses renamed the virus to Severe Acute Respiratory Syndrome Coronavirus 2 (SARS-CoV-2). Later, the WHO announced that the epidemic disease caused by SARS-CoV-2 to be Coronavirus Disease 2019 (COVID-19). After the outbreak of COVID-19, the Chinese government activated First-Level Public Health Emergency Response on January 26, 2020. While preventing and controlling the spread of the

\footnotetext{
${ }^{*}$ Corresponding author: Bin Sun, The Captain of the Medical Team from Qinghai to aid Hubei, Intensive Care Unit, Qinghai Provincial People's Hospital, Xining, Qinghai 810007, China. Tel.: +86 15897081207; E-mail: wanghao840323@163.com.
}

0928-7329 (c) 2022 - The authors. Published by IOS Press. This is an Open Access article distributed under the terms of the Creative Commons Attribution-NonCommercial License (CC BY-NC 4.0). 
disease, additional skilled medical personnel from other regions were recruited to Wuhan to assist in outbreak responses. On January 28, 2020, 5 medical staff from the Department of Intensive Care Medicine of our hospital accompanied Qinghai-to-Hubei medical team to help with the treatment of patients with coronavirus in Wuhan. In this report, we analyzed and summarized clinical features of 28 patients with COVID-19 treated by our team.

\section{Methods}

\subsection{Study population}

We collected the medical records of 28 severe and critically-ill COVID-19 patients admitted to the Department of Intensive Care Medicine at Xinzhou District People's Hospital in Wuhan from January 31 to March 17 of 2020. All patients were confirmed positive for COVID-19 by specific molecular testing and CT examination. The chest CT in the detection of COVID-19 showed bilateral ground-glass opacities and consolidations [2,3]. Inclusion criteria described: All patients admitted to the ICU meet the severe and critical diagnosis criteria in the "Notification on Issuing the New Coronavirus Pneumonia Diagnosis and Treatment Protocol (Seventh Trial Edition)" [4] issued by the General Office of the National Health Commission. Severe: Adults who meet any of the followings: a) Shortness of breath, $\mathrm{RR} \geqslant 30$ beats/min; b) in resting state $\mathrm{SaO} 2 \leqslant 93 \%$; c) Arterial blood Partial Pressure of Oxygen $(\mathrm{PaO} 2) /$ Fraction of Inspired Oxygen $(\mathrm{FiO} 2) \leqslant 300 \mathrm{mmHg}$, lung imaging shows within 24-48 hours, the lesions progressed significantly $>50 \%$ according to severe management. Critical: Those who meet one or more of the following conditions: a) Respiratory failure, and requirement of assisted ventilation; b) Shock; c) Combined with other organ failure, requirement of intensive care. Exclusion criteria: None.

\subsection{Data collection}

We collected each patient's general information, APACHE II score, SIRS score, SOFA score, and CURB-65 score upon entering the ICU. Vital signs, blood tests, biochemical tests, coagulation analysis, and blood gas analysis were performed. We also collected each patient's number of ICU hospitalization days and the prognosis when exiting the ICU. According to the different prognoses when leaving the ICU, we divided our cohort into the survival group and the mortality group. Blood routine testing was performed with a XN9000 analyzer (Sysmex Corporation, Japan). Biochemical analysis was performed with a Siemens ADVIA 2400 automatic biochemical analyzer. Brain natriuretic peptide (BNP) levels were measured with a DXi800 (Beckman Coulter, USA). Procalcitonin (PCT) was measured with a Cobas 8000 (Roche, Germany). C-reactive protein (CRP) levels were measured with an AU5800 (Beckman Coulter, USA). All detection reagents used the manufacturer's matching reagents.

\subsection{Treatments}

Intensive care, oxygen therapy (i.e., oxygen masks, non-invasive ventilators, invasive ventilators), acid-suppression agents to protect gastric mucosa (pantoprazole), anti-infection agents (sulbactam, cefoperazone, levofloxacin, azithromycin, imipenem), antiviral agents (oseltamivir, interferon, lopinavir/ritonavir tablets), hormones (methylprednisolone sodium succinate, dexamethasone), liver-protection agents (glutathione), nebulizer-inhalation agents (budesonide, terbutaline), phlegm/asthma-reduction agents (ambroxol, tanreqing, doxofylline), and other treatments (i.e., immunoglobulin, human albumin, Lianhua Qingwen capsules, Chinese herbal medicine) were administered to patients included in the present study. 


\subsection{Statistical analysis}

SPSS 22.0 statistical software was used for data analysis. Non-normally distributed measurement data are represented by P50 (P25, P75), and Mann-Whitney U test is used for comparison between the two groups (Survival and Death). The enumeration data was analyzed by $\chi^{2}$ test. Normally distributed measurement data were presented as mean \pm standard deviation, and the independent sample $t$ test was used for comparison between two groups. Significance level $a<0.05$ indicates that the difference is statistically significant.

\section{Results}

The general symptoms of patients included the following: dyspnea ( 3 out of 28 ), wheezing ( 8 out of 28), chest pain ( 1 out of 28), chest tightness (10 out of 28), cough (23 out of 28), expectoration ( 8 out of 28), fatigue ( 4 out of 28), sore throat (1 out of 28), and fever (22 out of 28). The highest body temperature fluctuated between $38.5-40.0^{\circ} \mathrm{C}$. Furthermore, the following additional ailments were found in our cohort: hypertension ( 5 out of 28 ), diabetes ( 3 out of 28 ), coronary heart disease ( 1 out of 28 ), chronic bronchitis ( 3 out of 28 ), hepatitis B (13 out of 28), syphilis ( 1 out of 28 ), adenovirus infection (3 out of 28), respiratory syncytial virus infection (1 out of 28), and coxsackie virus infection (1 out of 28).

The following hospital-admission measurements between the survival group and mortality group were significantly different $(P<0.05)$ : age, systolic blood pressure upon admission, lymphocyte count (LY), albumin (ALB), total bilirubin (TBIL), and lactate dehydrogenase (LDH). There were no significant differences in any other hospital-admission indicators between the two groups $(P>0.05)$ (Table 1$)$.

The following ICU-admission measurements between the survival group and mortality group were significantly different $(P<0.05)$ : APACHE II, CURB-65, SOFA, respiratory rate, systolic blood pressure, platelet count (PLT), PCT, ALB, creatinine (CREA), creatine kinase isoenzyme (CK-MB), lactate dehydrogenase ( $\mathrm{LDH})$, chloride ions $(\mathrm{Cl})$, prothrombin time (PT), international normalized ratio (INR), and $\mathrm{PaO} 2 / \mathrm{FiO} 2$. There were no significant differences in any of the remaining ICU-admission indicators between the two groups $(P>0.05)$ (Table 2$)$.

In terms of follow-ups, none of the deceased patients in the mortality group underwent an autopsy. The follow-ups were completed on May 8, 2020. Of the 17 surviving patients, two patients did not participate in the follow-ups. Among the 15 patients that participated in follow-ups, 12 patients were re-examined via computed tomography after discharge; and it was revealed that in 5 out of 12 of these patients, the exudate was not completely absorbed. Nucleic-acid re-examinations of all 15 patients that participated in follow-ups were negative.

\section{Discussion}

A total of 28 severe and critical patients were involved in this study, including 18 males and 10 females. The average age of the disease is $54.8 \pm 15.1$ years. The age distribution in this study is similar as that reported in other studies [5,6] but with higher male-female ratio. Among these patients, 15 out of 28 COVID-19 patients suffered from one or more underlying diseases, including hypertension, diabetes, coronary heart disease, and chronic bronchitis [7]. The median time from onset to doctor's visit was 7 days. Among them, the median time for patients in the death group was 9 days, but there was no statistical difference between the two medians. This is consistent with the average duration of 5.8 days 
Table 1

Admission indicators between the survival group and the death group

\begin{tabular}{|c|c|c|c|c|c|c|}
\hline Indicators & & Total & Survival group & Death group & Statistics & $P$ \\
\hline \multirow[t]{2}{*}{ Number gender } & Case & 28 & 17 & 11 & & \\
\hline & Male: Female & $18: 10$ & $9: 8$ & $9: 2$ & $X^{2}=1.331$ & 0.24 \\
\hline Age & Year & $54.8 \pm 15.1$ & $49.9 \pm 14.0$ & $62.4 \pm 14.0$ & $t=-2.302$ & 0.030 \\
\hline Onset to admission & Day & $7.0(4.3,12.0)$ & $7.0(4.0,16.5)$ & $9.0(5.0,12.0)$ & $Z=-0.189$ & 0.850 \\
\hline Admission to the ICU & Day & $5.0(0.3,7.0)$ & $7.0(4.5,8.5)$ & $2.0(0.0,4.0)$ & $Z=-2.828$ & 0.005 \\
\hline Admission temperature & ${ }^{\circ} \mathrm{C}$ & $36.8(36.3,37.4)$ & $37.0(36.5,38.0)$ & $36.6(36.3,37.0)$ & $Z=-1.818$ & 0.069 \\
\hline Admission heart rate & $/ \min$ & $87(83,104)$ & $86(81,101)$ & $98(86,108)$ & $Z=-1.650$ & 0.099 \\
\hline Admission respiratory rate & $/ \min$ & $20(20,24)$ & $20(20,22)$ & $23(20,31)$ & $Z=-1.826$ & 0.068 \\
\hline Admission systolic pressure & $\mathrm{mmHg}$ & $129 \pm 21$ & $123 \pm 18$ & $139 \pm 23$ & $t=-2.063$ & 0.049 \\
\hline Admission diastolic pressure & $\mathrm{mmHg}$ & $80 \pm 15$ & $76 \pm 14$ & $85 \pm 17$ & $t=-1.631$ & 0.115 \\
\hline Admission WBC & $\times 10^{9} / \mathrm{L}$ & $7.7 \pm 3.5$ & $7.2 \pm 4.0$ & $8.4 \pm 2.6$ & $t=-0.924$ & 0.364 \\
\hline Admission LY & $\times 10^{9} / \mathrm{L}$ & $0.86 \pm 0.36$ & $0.98 \pm 0.38$ & $0.67 \pm 0.23$ & $t=2.462$ & 0.021 \\
\hline Admission HGB & $\mathrm{g} / \mathrm{L}$ & $141 \pm 19$ & $141 \pm 19$ & $142 \pm 19$ & $t=-0.126$ & 0.901 \\
\hline Admission PLT & $\times 10^{9} / \mathrm{L}$ & $183 \pm 63$ & $189 \pm 74$ & $173 \pm 39$ & $t=0.741$ & 0.466 \\
\hline Admission PCT & $\mathrm{ng} / \mathrm{ml}$ & $\begin{array}{l}0.20(0.13,0.28) \\
(N=24)\end{array}$ & $\begin{array}{l}0.2(0.1,0.2) \\
(N=14)\end{array}$ & $\begin{array}{l}0.2(0.2,0.78) \\
(N=10)\end{array}$ & $Z=-1.705$ & 0.088 \\
\hline Admission BNP & $\mathrm{ng} / \mathrm{L}$ & $\begin{array}{l}741(269,917) \\
(N=11)\end{array}$ & $\begin{array}{l}377(50,781) \\
(N=5)\end{array}$ & $\begin{array}{l}829(568,2205) \\
(N=6)\end{array}$ & $Z=$ & 0.144 \\
\hline Admission ALT & $\mathrm{U} / \mathrm{L}$ & $39(31,54)$ & $36(30,49)$ & $41(31,57)$ & $Z=-0.801$ & 0.423 \\
\hline Admission AST & $\mathrm{U} / \mathrm{L}$ & $31(23,42)$ & $27(23,35)$ & $41(28,59)$ & $Z=-1.600$ & 0.110 \\
\hline Admission ALB & $\mathrm{g} / \mathrm{L}$ & $\begin{array}{l}34.7 \pm 6.3 \\
(N=27)\end{array}$ & $\begin{array}{l}37.5 \pm 5.6 \\
(N=16)\end{array}$ & $30.7=$ & $t=3.198$ & 0.004 \\
\hline Admission TBIL & $\mathrm{umol} / \mathrm{L}$ & $\begin{array}{l}14.0 \pm 6.7 \\
(N=25)\end{array}$ & $\begin{array}{l}11.6 \pm 4.6 \\
(N=15)\end{array}$ & $\begin{array}{l}17.6 \pm 8.0 \\
(N=10)\end{array}$ & $t=-1$ & 0.02 \\
\hline Admission BUN & $\mathrm{mmol} / \mathrm{L}$ & $\begin{array}{l}6.1 \pm 2.7 \\
(N=20)\end{array}$ & $\begin{array}{l}5.1 \pm 2.1 \\
(N=11)\end{array}$ & $\begin{array}{l}7.3 \pm 3.0 \\
(N=9)\end{array}$ & $t=-1.886$ & 0.076 \\
\hline Admission CREA & umol/L & $\begin{array}{l}74(71,85) \\
(N=27)\end{array}$ & $\begin{array}{l}71(66,89) \\
(N=16)\end{array}$ & $74(72,85)$ & $Z=-1.115$ & 0.265 \\
\hline on GLU & $\mathrm{mmol} / \mathrm{L}$ & $5.9(4.9,6.9)$ & $5.8(4.6,6.3)$ & $6.6(5$ & $Z=-1.671$ & 0.095 \\
\hline Admission CK & $\mathrm{U} / \mathrm{L}$ & $148(62,337)$ & $188(76,401)$ & $83(50,165)$ & $Z=-1.201$ & 0.230 \\
\hline Admission CK-MB & $\mathrm{U} / \mathrm{L}$ & $16(10,25)$ & $11(10,26)$ & $17(11,25)$ & $Z=-0.969$ & 0.333 \\
\hline Admission LDH & $\mathrm{U} / \mathrm{L}$ & $368(301,448)$ & $315(268,407)$ & $502(386,638)$ & $Z=-3.058$ & 0.002 \\
\hline Admission $\mathrm{K}$ & $\mathrm{mmol} / \mathrm{L}$ & $5.3 \pm 0.9$ & $4.5 \pm 0.9$ & $4.1 \pm 0.9$ & $t=1.056$ & 0.301 \\
\hline Admission $\mathrm{Na}$ & $\mathrm{mmol} / \mathrm{L}$ & $136 \pm 5$ & $136 \pm 3$ & $137 \pm 6$ & $t=-0.666$ & 0.511 \\
\hline Admission $\mathrm{Cl}$ & $\mathrm{mmol} / \mathrm{L}$ & $101 \pm 4$ & $100 \pm 2$ & $102 \pm 6$ & $t=-1.113$ & 0.288 \\
\hline Admission $\mathrm{Ca}$ & $\mathrm{mmol} / \mathrm{L}$ & $2.4(2.2,2.5)$ & $2.4(2.3,2.5)$ & $2.3(2.1,2.4)$ & $Z=-1.551$ & 0.121 \\
\hline Admission $\mathrm{P}$ & $\mathrm{mmol} / \mathrm{L}$ & $1.0(0.8,1.2)$ & $1.1(1.0,1.2)$ & $0.9(0.6,1.1)$ & $Z=-1.735$ & 0.083 \\
\hline Admission PT & sec. & $12.2 \pm 1.9$ & $11.8 \pm 2.0$ & $12.8 \pm 1.8$ & $t=-1.305$ & 0.203 \\
\hline Admission APTT & sec. & $31.2 \pm 6.1$ & $30.3 \pm 6.1$ & $32.5 \pm 6.1$ & $t=-0.922$ & 0.365 \\
\hline Admission INR & & $1.05 \pm 0.17$ & $1.02 \pm 0.17$ & $1.10 \pm 0.16$ & $t=-1.247$ & 0.223 \\
\hline Admission FIB & $\mathrm{g} / \mathrm{L}$ & $3.67 \pm 0.67$ & $3.58 \pm 0.53$ & $3.81 \pm 0.87$ & $t=-0.900$ & 0.377 \\
\hline Admission DD & $\mathrm{mg} / \mathrm{L}$ & $0.9(0.4,2.5)$ & $1.0(0.5,2.1)$ & $0.7(0.3,2.9)$ & $Z=-0.118$ & 0.906 \\
\hline
\end{tabular}

from the onset of the disease to the first visit that some studies have shown (95\% CI 4.3 to 7.5 days) similar to the previous studies [8-10]. In clinical manifestations, the symptoms of 22/28 patients are cough and fever, which are consistent with other reported studies [11-14]. 13/28 of the patients had viral hepatitis B but it is unclear whether viral hepatitis B renders people more susceptible to COVID-19. Though other studies have shown that some COVID-19 patients developed symptoms of intestinal involvement [15], this group of patients did not show any gastrointestinal symptoms. Overall, the median body temperature of all patients at admission was $36.8^{\circ} \mathrm{C}$, and there was no manifestation of elevated body temperature, which may be related to the use of fever reducers after the patients found themselves with fever before admission. The death group had a higher heart rate than the survivors (98 vs 86 beats/min) upon admission, but 
Table 2

Indicators between the survival group and the death group when admitted to ICU

\begin{tabular}{|c|c|c|c|c|c|c|}
\hline Indicators & & Total & Survival group & Death group & Statistics & $P$ \\
\hline Number & Case & 28 & 17 & 11 & & \\
\hline Admitted to ICU APACHE II & & $7.5(5.0,11.0)$ & $6.0(3.5,9.0)$ & $13.0(9.0,24.0)$ & $Z=-3.096$ & 0.002 \\
\hline Admitted to ICU CURB-65 & & $1.0(0.3,2.0)$ & $1.0(0.0,1.0)$ & $3.0(1.0,3.0)$ & $Z=-3.607$ & $<0.001$ \\
\hline Admitted to ICU SIRS & & $2.0(2.0,3.0)$ & $2.0(1.0,2.5)$ & $2.0(2.0$ & $Z=-1.565$ & 0.117 \\
\hline Admitted to ICU SOFA & & $3.0(3.0,5.0)$ & $3.0(2.0,3.0)$ & $6.0(4.0,7.0)$ & $Z=-3.666$ & $<0.001$ \\
\hline Admitted to ICU temperature & ${ }^{\circ} \mathrm{C}$ & $37.0 \pm 0.8$ & $37.1 \pm 0.9$ & $36.9 \pm 0.6$ & $t=0.596$ & 0.556 \\
\hline Admitted to ICU heart rate & $/ \mathrm{min}$ & $92 \pm 14$ & $88 \pm 16$ & $97 \pm 10$ & $t=-1.679$ & 0.105 \\
\hline Admitted to ICU respiratory rate & $/ \mathrm{min}$ & $26(21,35)$ & $22(20,26)$ & $33(31,43)$ & $Z=-3.421$ & 0.001 \\
\hline Admitted to ICU systolic pressure & $\mathrm{mmHg}$ & $132 \pm 16$ & $126 \pm 14$ & $141 \pm 15$ & $t=-2.691$ & 0.012 \\
\hline Admitted to ICU diastolic pressure & $\mathrm{mmHg}$ & $77 \pm 14$ & $75 \pm 13$ & $79 \pm 17$ & $t=-0.778$ & 0.443 \\
\hline Admitted to ICU WBC & $\times 10^{9} / \mathrm{L}$ & $10.5 \pm 5.2$ & $9.2 \pm 5.8$ & $12.5 \pm 3.5$ & $t=-1.695$ & 0.102 \\
\hline Admitted to ICU LY & $\times 10^{9} / \mathrm{L}$ & $0.64(0.53,0.97)$ & $0.69(0.57,1.00)$ & $0.58(0.49,0.95)$ & $Z=-0.895$ & 0.371 \\
\hline Admitted to ICU HGB & $\mathrm{g} / \mathrm{L}$ & $130 \pm 20$ & $125 \pm 19$ & $136 \pm 19$ & $t=-1.565$ & 0.130 \\
\hline Adm & $\times 10^{9} / \mathrm{L}$ & $183(134,287)$ & $250(156,377)$ & $142(11$ & $Z=-2.541$ & 0.011 \\
\hline Adr & $\mathrm{ng} / \mathrm{ml}$ & $\begin{array}{l}0.2(0.2,0.4) \\
(N=26)\end{array}$ & $\begin{array}{l}0.2(0.1,0.2) \\
(N=15)\end{array}$ & $0.3(0$ & $Z=-2$ & 0.015 \\
\hline Adm & $\mathrm{ng}$ & $\begin{array}{l}952(751,3461) \\
(N=12)\end{array}$ & $\begin{array}{l}886(641,9716) \\
(N=6)\end{array}$ & $\begin{array}{l}1731(723,11575) \\
(N=6)\end{array}$ & $Z=-0.401$ & 0 . \\
\hline $\mathrm{dm}$ & $\mathrm{U} / \mathrm{L}$ & $35(25,54)$ & $31(23,45)$ & $38(32,68)$ & $Z=-1.506$ & 0.132 \\
\hline Admitted to ICU AST & $\mathrm{U} / \mathrm{L}$ & $33(24,53)$ & 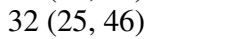 & $33(2$ & $Z=-0.283$ & 0.777 \\
\hline Admitted to ICU ALB & $\mathrm{g} / \mathrm{L}$ & $29.4(27.1,33.2)$ & $31(29,34)$ & $27(26,29)$ & $Z=-2.872$ & 0.004 \\
\hline to ICU TBIL & umol/L & $19.8(13.1,26.2)$ & $18.7(12.5,20.9)$ & $26.4(17.4,35.7)$ & $Z=-1.624$ & 0.104 \\
\hline o ICU BUN & $\mathrm{mmol} / \mathrm{L}$ & $6.8(4.6,9.7)$ & 5.5( & 9.2( & $Z=-1$ & 0.082 \\
\hline J CREA & umol/L & 72 & 6. & 77( & $Z=-2$ & 0.045 \\
\hline Adr & $\mathrm{mmol} / \mathrm{L}$ & 6.2 & 8) & 6.3 & $Z=-$ & 944 \\
\hline Adr & $\mathrm{U} / \mathrm{L}$ & 83 & 7) & 4) & $Z=$ & 0.707 \\
\hline Ad & $\mathrm{U} / \mathrm{L}$ & 15 & 1 & 17 & $Z=-$ & 0.011 \\
\hline U LDH & $\mathrm{U} / \mathrm{L}$ & $419(347,640)$ & $5,441)$ & $4,722)$ & $Z=-3.082$ & 0.002 \\
\hline ICU K & $\mathrm{mmol} / \mathrm{L}$ & $3.9 \pm 0.6$ & $4.0 \pm$ & $3.6 \pm 0.6$ & $t=1.824$ & 0.080 \\
\hline to ICU Na & $\mathrm{mmol} / \mathrm{L}$ & $137 \pm 5$ & $136 \pm 4$ & $138 \pm 6$ & $t=-1.516$ & 0.142 \\
\hline Adn & $\mathrm{mmol} / \mathrm{L}$ & $102(100$ & 102 & $103(103,105)$ & $Z=-1.965$ & 0.049 \\
\hline Adr & $\mathrm{mmol} / \mathrm{L}$ & $2.2(2$ & 2.3 & $2.2(2$ & $Z=-1.712$ & 0.087 \\
\hline Adr & $\mathrm{mmol} / \mathrm{L}$ & $0.9 \pm 0.2$ & $0.9=$ & $0.8 \pm$ & $t=1.769$ & 0.089 \\
\hline Ad & sec. & $12.4(11.5$ & 11.8( & 14.3( & $Z=-2.542$ & 0.011 \\
\hline U APTT & sec. & $.7,33.8)$ & 26.5 & 31.6( & $Z=-1.835$ & 0.067 \\
\hline I to ICU INR & & $1.07(0.99,1.25)$ & $1.01(0.94,1.09)$ & $1.23(1.03,1.30)$ & $Z=-2.424$ & 0.015 \\
\hline Admitted to ICU FIB & $\mathrm{g} / \mathrm{L}$ & $3.47(2.76,4.07)$ & $3.66(3.16,4.13)$ & $2.87(1.57,3.65)$ & $Z=-1.576$ & 0.115 \\
\hline Admitted to ICU DD & $\mathrm{mg} / \mathrm{L}$ & $2.47(0.61,6.59)$ & $2.77(0.79,6.13)$ & $1.35(0.28,12.75)$ & $Z=-0.353$ & 0.724 \\
\hline Admitted to ICU PH & & $7.49 \pm 0.07$ & $7.49 \pm 0.05$ & $7.49 \pm 0.09$ & $t=-0.177$ & 0.861 \\
\hline Admitted to ICU $\mathrm{PCO}_{2}$ & $\mathrm{mmHg}$ & $31 \pm 6$ & $32 \pm 6$ & $29 \pm 5$ & $t=1.482$ & 0.150 \\
\hline to ICU $\mathrm{PO}_{2}$ & $\mathrm{mmHg}$ & $69(60,89)$ & $82(64,1$ & $62(52,6$ & $Z=-2.660$ & 0.008 \\
\hline o ICU Lac & $\mathrm{mmol} / \mathrm{L}$ & $1.40(1.03,2.20)$ & $1.4(0.9,1.9)$ & $1.5(1.1,2.6)$ & $Z=-1.132$ & 0.258 \\
\hline o ICU FiO2 & & $1,0.60)$ & $39,0.55)$ & $0.60(0.45,0.60)$ & $Z=-2.186$ & 0.029 \\
\hline $\mathrm{PO}_{2} / \mathrm{FiO} 2$ & & $172 \pm 89$ & $209 \pm 97$ & $115 \pm 20$ & $t=3.854$ & 0.001 \\
\hline
\end{tabular}

the difference was not statistically significant. The median respiratory rate in the death group was 23 breaths/min, which was also higher than 20 breaths/min in the survival group, and the difference was also not statistically significant. The mean systolic blood pressure and diastolic blood pressure of the death group were higher than those of the survival group (139 vs $123 \mathrm{mmHg} ; 85 \mathrm{vs} 76 \mathrm{mmHg}$ ). Three patients in the death group and 2 patients in the survival group were in combination with high blood pressure. We exclude the possibility of pre-existing hypertension-causing diseases. The possible reason is that hypoxia leads to an increase in the body's heart rate, an increase in myocardial contractility, and 
ultimately an increase in cardiac output [16]. Laboratory examinations at admission showed that the lymphocyte count (LY) of patients in the survival group was significantly increased, but the lymphocyte counts of the two groups were significantly lower than the normal value, which is consistent with previous studies [17-19]. Lymphocytes play a central role in the immune response. Lymphocytes mainly include $\mathrm{T}$ lymphocytes and B lymphocytes. Unfortunately, due to limited conditions, we did not make further classification of lymphocyte subgroups. Lymphocyte reduction in the death group indicates the cells responsible for immune response were severely damaged. Related studies have also shown that a decrease in lymphocyte counts indicates a poor prognosis [20]. The albumin (ALB) level of the survival group was significantly higher than that of the death group. The decrease in albumin in the body is mainly due to the decrease in synthesis and the increase in consumption during the course of the disease. The decrease in synthesis may be due to insufficient intake of nutrients and impaired liver function, and consumption is directly manifested in the stress response caused by COVID-19, which directly causes albumin to be consumed as calories. The total bilirubin (TBIL) levels of the surviving group were significantly reduced compared to the death group. There was no significant difference in hemoglobin levels between the two groups, and the levels were largely within the normal range, so the increase in TBIL caused by the blood system can basically be ruled out. It is more likely that the rise of TBIL levels is the result of impaired liver functions. Correspondingly, the liver function tests revealed that liver enzymes of the death group were also higher than those of the survival group, but there was no statistical difference. There was no difference in renal function indexes between the two groups. The lactate dehydrogenase (LDH) levels of the survival group were significantly reduced compared to the death group. LDH is classified into 5 subtypes. LDH1 and LDH2 are mainly expressed when myocardial tissue is damaged, LDH3 is expressed when lung tissue is damaged, and LDH4 and LDH5 are expressed when liver tissue is damaged. The LDH levels of all patients in the present study were significantly increased compared to those of normal values, and those of the mortality group were even more increased. It may be caused by damage to lung tissue, heart tissue and liver tissue. Unfortunately, we did not do subtype testing, so we could not exclude that SARS-CoV-2 infection causes damage to target organs other than the lung when the disease is severe. Some studies $[9,21,22]$ also show that the above indicators of patients are obviously abnormal. Through coagulation test we found that the coagulation indexes were not significantly higher than the normal value, and the difference between the survival group and the death group was not statistically significant. The possible reason is that at the initial stage of the disease, even if the liver function is damaged, the coagulation function is not affected. However, as the disease progresses, changes in coagulation function may occur.

The median time from admission to ICU for this group of patients is 5 days. The median time for the survival group is 7 days, and the median time for the death group is 2 days. The difference in age between the two groups indicates that the disease progresses more rapidly and provide a higher risk of death in older patients (average age of the death group is 62.4 years) [23]. Upon entering the ICU due to disease worsening, the APACHE II score, the CURB-65 score and the SOFA score of the survival group were lower than those of the death group. Higher scores indicate a poor prognosis, which is in consistency with our observations. When entering the ICU, the respiratory rates of patients in the death group were significantly higher than those of patients in the survival group (33 vs 22 breaths/min). Hence, as the disease worsens, the increase in respiratory rate is the major clinical manifestation of severe patients. The respiratory failure may be related to the nerve invasion of SARS-CoV2 [24]. The average systolic blood pressures of the death group rose further (139 vs $141 \mathrm{mmHg}$ ) after entering the ICU, and were significantly higher than that of the survivors ( $141 \mathrm{vs} 126 \mathrm{mmHg}$ ). The increase of blood pressure without significant changes in heart rate, may be the result of activation of the receptors that cause contraction of 
blood vessels as response to stress. As the disease progresses, the two groups have significant differences in platelet count (PLT). Platelets are key regulators of intravascular immunity and inflammation in the host. In addition to participating in the clotting process, platelets can also directly identify, isolate and kill pathogens, activate and guide neutrophils to the site of infection and inflammation, enhance their ability to engulf and kill pathogens, inducing unique effective functions [25]. Our study shows that the PLT counts of the death group are lower than those of the survival group. The reason may be that platelets are recruited and consumed in the body's inflammatory response and the damage of the body's organs caused by COVID-19, which has adverse reactions to bone marrow hematopoietic cells, resulting in decreased platelet synthesis [26], related studies have shown that the reduction of platelets can increase the risk of death in the hospital [27-29]. The PT and INR values of the survival group and the death group were statistically different, suggesting that coagulation disorders may be related to the disease severity. There is no statistical difference in the FDP and DDL values between the two groups, but if these indexes are significantly higher than the normal value in the ICU, it also indicates disorders of the fibrinolytic system. Related research [30-32] suggests that coagulation plays an important role in the progression of the disease. The increase in procalcitonin (PCT) in the dead group indicates secondary bacterial infection during SARS-CoV-2 infection. Multiple infections directly worsened the disease and aggravated the body's toxic reaction [33,34]. Albumin (ALB) levels in the two groups were lower after admission to the ICU than at admission ( $37 \mathrm{vs} 31 ; 31 \mathrm{vs} 27 \mathrm{~g} / \mathrm{L}$ ), but the death group decreased more significantly ( $27 \mathrm{vs}$ $31 \mathrm{~g} / \mathrm{L}$ ). This can be explained by further damage of the liver functions, revealed by coagulation disorders that occurred in the later stages of the disease, demonstrated by prolonged prothrombin time (PT). Renal function did not change significantly on admission, but when admitted to the ICU, the creatinine (CREA) levels of the death group were significantly increased. As SARS-CoV-2 infection causes damage to multiple organs, the lactate dehydrogenase (LDH) index gradually increased compared with levels at admission (368 vs $419 \mathrm{U} / \mathrm{L}$ ), suggesting that lung, liver, and heart tissue damage was further aggravated. In the meantime, creatine kinase isoenzyme (CK-MB) levels are significantly higher in the death group than in the survival group, also indicating that SARS-CoV-2 gradually increase its toxic effect on the myocardium as the disease progresses [35-38]. The blood chloride ion $(\mathrm{Cl})$ levels in the death group were higher, but still within the normal range. The cause of the increase may be respiratory alkalosis. In the blood gas analysis, the differences in the arterial Partial Pressure of Oxygen $(\mathrm{PaO} 2)$ and Fraction of Inspired Oxygen (FiO2) were statistically different between the two groups, which directly reflected the difference in the degree of lung injury between the two groups. The oxygenation index of the death group was significantly decreased (115 vs 209, $P<0.05$ ). Many patients infected with SARS-CoV-2, especially critically ill patients, had complications, including ARDS, shock, acute kidney injury, acute myocardial injury and secondary infections [39].

The chloroquine or remdesivir may be effective in the treatment of COVID-19 [40,41]. Both Pfizer and Moderna have developed and are distributing COVID-19 vaccines. Treatments for the patients in the present study included intensive care, oxygen therapy (oxygen by mask, non-invasive ventilator, or invasive ventilator), acid-suppression agents to protect gastric mucosa, anti-infection agents, antivirus agents, hormonal application, liver protection, immunoglobulin, human albumin, Chinese herbal medicines, and other treatments [42]. The treatments achieved moderate outcomes, resulting in a mortality rate of 39.3\% (11/28) in our present study. However, the mortality rate reported in the literature varies between $1.36 \%$ and $15 \%[43,44]$. The reason for the higher mortality rate among the patients in the present study may be due to all patients in this group being severely ill. 


\section{Conclusion}

Fever and cough on admission were the main symptoms of COVID-19 patients in our present study, and these symptoms were often accompanied by chest pain, chest tightness, and difficulty breathing. At present, chloroquine and hydroxychloroquine may be effective in the treatment of COVID-19, and antibiotics can be used to control the infection when secondary bacterial infection occurs. Additionally, the use of Chinese traditional medicine may improve the overall condition of the immune system, thereby increasing the survival rate of COVID-19 patients. At present, the in-hospital mortality rate of COVID-19 is $28 \%-62 \%$, and $81 \%$ of these patients require mechanical ventilation $[20,45,46]$. The drugs that protect the liver and heart may improve the survival rate of patients with severe COVID-19. Hence, further research needed in order to control COVID-19 and reduce the mortality rate of severely ill patients.

\section{Acknowledgments}

The authors would like to thank their colleagues, Guibin Jia, Xiaolin Sun, and Qingjun Shi, at Wuhan Xinzhou District People's Hospital for their collaboration. They also thank Zhaozhi Sun from Heidelberg University Hospital for reviewing and editing the manuscript. We thank LetPub (www.letpub.com) for their linguistic assistance during the preparation of this manuscript.

\section{Conflict of interest}

None to report.

\section{References}

[1] Lai Ch, Liu YH, Wang CY, et al. Asymptomatic carrier state, acute respiratory disease, and pneumonia due to severe acute respiratory syndrome coronavirus 2 (SARS-CoV-2): Facts and myths. Journal of Microbiology, Immunology and Infection. 2020; 53: 404-412.

[2] Ahn D, Shin H, Kim M, et al. Current status of epidemiology, diagnosis, therapeutics, and vaccines for novel coronavirus disease 2019 (COVID-19). J. Microbiol. Biotechnol. 2020; 30(3): 313-324. doi: 10.4014/jmb.2003.03011.

[3] Bertolazzi P, Melo HJF. A importancia da Tomografia Computadorizada no diagnóstico da COVID-19. The importance of Computed Tomography in diagnosis of COVID-19. Arq Med Hosp Fac Cienc Med Santa Casa São Paulo. 2020; 65: e11. doi: 10.26432/1809-3019.2020.65.011.

[4] Office of the National Administration of Traditional Chinese Medicine, National Health Commission. Notice on the issuance of the COVID-19 protocol (Trial Seventh Edition) [EB/OL]. (2020-2-18) [2020-12-24]. http://www.cac.gov.cn/ 2020-03/04/c_1584872634644633.htm.

[5] Lu HZ, Stratton CW, Tang YW. Outbreak of pneumonia of unknown etiology in Wuhan, China: The mystery and the miracle. J Med Virol. 2020 Apr; 92(4): 401-402. doi: 10.1002/jmv.25678.

[6] Hui DS, Azhar EI, Madani TA, et al. The continuing 2019-nCoV epidemic threat of novel coronaviruses to global health - The latest 2019 novel coronavirus outbreak in Wuhan, China. Int J Infect Dis. 2020 Feb; 91: 264-266. doi: 10.1016/j.ijid.2020.01.009.

[7] Wan YS, Shang J, Graham R, et al. Receptor recognition by the novel coronavirus from Wuhan: An analysis based on decade-long structural studies of SARS coronavirus. J Virol. 2020 Mar 17; 94(7): e00127-20. doi: 10.1128/JVI.00127-20.

[8] Chan JFW, Yuan SF, Kok KH, et al. A familial cluster of pneumonia associated with the 2019 novel coronavirus indicating person-to-person transmission: A study of a family cluster. Lancet. 2020 Feb 15; 395(10223): 514-523. doi: 10.1016/S0140-6736(20)30154-9.

[9] Backer JA, Klinkenberg D, Wallinga J, et al. Incubation period of 2019 novel coronavirus (2019-nCoV) infections among travellers from Wuhan, China, 20-28 January 2020. Euro Surveill. 2020 Feb; 25(5): 2000062. doi: 10.2807/15607917.ES.2020.25.5.2000062. 
[10] Lauer SA, Grantz KH, Bi QF, et al. The incubation period of coronavirus disease 2019 (COVID-19) from publicly reported confirmed cases: Estimation and application. Ann Intern Med. 2020 May 5; 172(9): 577-582. doi: 10.7326/M20-0504.

[11] Huang CL, Wang YM, Li XW, et al. Clinical features of patients infected with 2019 novel coronavirus in Wuhan, China. Lancet. 2020 Feb 15; 395(10223): 497-506. doi: 10.1016/S0140-6736(20)30183-5.

[12] Zhu N, Zhang DY, Wang WL, et al. A novel coronavirus from patients with pneumonia in China, 2019. N Engl J Med. 2020 Feb 20; 382(8): 727-733. doi: 10.1056/NEJMoa2001017.

[13] Guan WJ, Ni ZY, Hu Y, et al. Clinical characteristics of coronavirus disease 2019 in China. N Engl J Med. 2020 Apr 30; 382(18): 1708-1720. doi: 10.1056/NEJMoa2002032.

[14] Li Q, Guan XH, Wu P, et al. Early transmission dynamics in Wuhan, China, of novel coronavirus-infected pneumonia. N Engl J Med. 2020 Mar 26; 382(13): 1199-1207. doi: 10.1056/NEJMoa2001316.

[15] Habibzadeh P, Stoneman EK. The novel coronavirus: A bird's eye view. Int J Occup Environ Med. 2020 Apr; 11(2): 65-71. doi: 10.15171/ijoem.2020.1921.

[16] Siebenmann C, Lundby C. Regulation of cardiac output in hypoxia. Scand J Med Sci Sports. 2015 Dec; 25(Suppl 4): 53-9. doi: 10.1111/sms.12619.

[17] Bai Y, Yao LS, Wei T, et al. Presumed asymptomatic carrier transmission of COVID-19. JAMA. 2020 Feb 21; 323(14): 1406-1407. doi: 10.1001/jama.2020.2565.

[18] Wang DW, Hu B, Hu C, et al. Clinical characteristics of 138 hospitalized patients with 2019 novel coronavirus-infected pneumonia in Wuhan, China. JAMA. 2020 Feb 7; 323(11): 1061-1069. doi: 10.1001/jama.2020.1585.

[19] Chen NS, Zhou M, Dong X, et al. Epidemiological and clinical characteristics of 99 cases of 2019 novel coronavirus pneumonia in Wuhan, China: A descriptive study. Lancet. 2020 Feb 15; 395(10223): 507-513. doi: 10.1016/S01406736(20)30211-7.

[20] Henry BM, Oliveira MHS, Benoit S, et al. Hematologic, biochemical and immune biomarker abnormalities associated with severe illness and mortality in coronavirus disease 2019 (COVID-19): A meta-analysis. Clin Chem Lab Med. 2020 Jun 25; 58(7): 1021-1028. doi: 10.1515/cclm-2020-0369.

[21] Yuan J, Zou RR, Zeng LJ, et al. The correlation between viral clearance and biochemical outcomes of 94 COVID-19 infected discharged patients. Inflamm Res. 2020 Jun; 69(6): 599-606. doi: 10.1007/s00011-020-01342-0.

[22] Liu YX, Yang Y, Zhang C, et al. Clinical and biochemical indexes from 2019-nCoV infected patients linked to viral loads and lung injury. Sci China Life Sci. 2020 Mar; 63(3): 364-374. doi: 10.1007/s11427-020-1643-8.

[23] Schalekamp S, Huisman M, Dijk RA, et al. Model-based prediction 13 of critical illness in hospitalized patients with COVID-19. Radiology. 2021; 298(1): E46-E54. doi: 10.1148/radiol.2020202723.

[24] Li YC, Bai WZ, Hashikawa T. The neuroinvasive potential of SARS-CoV2 may play a role in the respiratory failure of COVID-19 patients. J Med Virol. 2020 Jun; 92(6): 552-555. doi: 10.1002/jmv.25728.

[25] Qu R, Ling Y, Zhang YHZ, et al. Platelet-to-lymphocyte ratio is associated with prognosis in patients with coronavirus disease-19. J Med Virol. 2020 Mar 17. doi: 10.1002/jmv.25767.

[26] Mo PZ, Xing YY, Xia Y, et al. Clinical characteristics of refractory COVID-19 pneumonia in Wuhan, China. Clin Infect Dis. 2020 Mar 16; ciaa270. doi: 10.1093/cid/ciaa270.

[27] Yang XB, Yang QY, Wang YX, et al. Thrombocytopenia and its association with mortality in patients with COVID-19. J Thromb Haemost. 2020 Jun; 18(6): 1469-1472. doi: 10.1111/jth.14848.

[28] Thachil J. What do monitoring platelet counts in COVID-19 teach us. J Thromb Haemost. 2020 Apr 28. doi: 10.1111/ jth.14879.

[29] Salamanna F, Maglio M, Landini MP, et al. Platelet functions and activities as potential hematologic parameters related to coronavirus disease 2019 (Covid-19). Platelets. 2020 Jul 3; 31(5): 627-632. doi: 10.1080/09537104.2020.1762852.

[30] Connors JM, Levy JH. COVID-19 and its implications for thrombosis and anticoagulation. Blood. 2020; 135(23): 2033-2040. doi: 10.1182/blood.2020006000.

[31] Lippi G, Plebani M, Henry BM. Thrombocytopenia is associated with severe coronavirus disease 2019 (COVID-19) infections: A meta-analysis. Clin Chim Acta. 2020; 506: 145-148. doi: 10.1016/j.cca.2020.03.022.

[32] Levi M, Thachil J, Iba T, et al. Coagulation abnormalities and thrombosis in patients with COVID-19. Lancet Haematol. 2020 Jun; 7(6): e438-e440. doi: 10.1016/S2352-3026(20)30145-9.

[33] Huang I, Pranata R, Lim MA, et al. C-reactive protein, procalcitonin, D-dimer, and ferritin in severe coronavirus disease-2019: A meta-analysis. Ther Adv Respir Dis. 2020; 14: 1-14. doi: 10.1177/1753466620937175.

[34] Zhou C, Chen Y, Ji Y, et al. Increased serum levels of hepcidin and ferritin are associated with severity of COVID-19. Med Sci Monit. 2020; 26: e926178. doi: 10.12659/MSM.926178.

[35] Zheng YY, Ma YT, Zhang JY, et al. COVID-19 and the cardiovascular system. Nat Rev Cardiol. 2020 May; 17(5): 259-260. doi: 10.1038/s41569-020-0360-5.

[36] Hendren NS, Drazner MH, Bozkurt B, et al. Description and proposed management of the acute COVID-19 cardiovascular syndrome. Circulation. 2020 Jun 9; 141(23): 1903-1914. doi: 10.1161/CIRCULATIONAHA.120.047349.

[37] Asokan I, Rabadia SV, Yang EH. The COVID-19 pandemic and its impact on the cardio-oncology population. Curr Oncol Rep. 2020 May 28; 22(6): 60. doi: 10.1007/s11912-020-00945-4. 
[38] Zhu H, Rhee JW, Cheng P, et al. Cardiovascular complications in patients with COVID-19: Consequences of viral toxicities and host immune response. Curr Cardiol Rep. 2020 Apr 21; 22(5): 32. doi: 10.1007/s11886-020-01292-3.

[39] Harapan H, Itoh N, Yufika A, et al. Coronavirus disease 2019 (COVID-19): A literature review. J Infect Public Health. 2020 May; 13(5): 667-673. doi: 10.1016/j.jiph.2020.03.019.

[40] Meo SA, Klonoff DC, Akram J. Efficacy of chloroquine and hydroxychloroquine in the treatment of COVID-19. Eur Rev Med Pharmacol Sci. 2020; 24(8): 4539-4547. doi: 10.26355/eurrev_202004_21038.

[41] Spinner CD, Gottlieb RL, Criner G, et al. Effect of Remdesivir vs Standard Care on Clinical Status at 11 Days in Patients wth Moderate COVID-19. A Randomized Clinical Trial. JAMA. doi: 10.1001/jama.2020.16349.

[42] Li H, Liu SM, Yu XH, et al. Coronavirus disease 2019 (COVID-19): Current status and future perspectives. Int J Antimicrob Agents. 2020 May; 55(5): 105951. doi: 10.1016/j.ijantimicag.2020.105951.

[43] Sun P, Lu XS, Xu C, et al. Understanding of COVID-19 based on current evidence. J Med Virol. 2020 Jun; 92(6): 548-551. doi: $10.1002 / j m v .25722$.

[44] Jiang F, Deng LH, Zhang LQ, et al. Review of the clinical characteristics of coronavirus disease 2019 (COVID-19). J Gen Intern Med. 2020 May; 35(5): 1545-1549. doi: 10.1007/s11606-020-05762-w.

[45] Yang XB, Yu Y, Xu JQ, et al. Clinical course and outcomes of critically ill patients with SARS-CoV-2 pneumonia in Wuhan, China: A single-centered, retrospective, observational study. Lancet Respir Med. 2020 May; 8(5): 475-481. doi: 10.1016/S2213-2600(20)30079-5.

[46] Zhou F, Yu T, Du RH, et al. Clinical course and risk factors for mortality of adult inpatients with COVID-19 in Wuhan, China: A retrospective cohort study. Lancet. 2020 Mar 28; 395(10229): 1054-1062. doi: 10.1016/S0140-6736(20)30566-3. 